\title{
The end of the Stability and Growth Pact?
}

\author{
Stefan Collignon ${ }^{1}$ \\ European Institute, The London School of Economics and Political little case Science, \\ Houghton Street, London WC 2A 2AE, Great Britain
}

Fiscal policy is the incomplete chapter in the macroeconomic arrangements agreed at Maastricht. The Stability and Growth Pact (SGP) was an attempt to patch it up, but it failed. We need to understand: why?

When the Ecofin Council in November 2003 voted against proceeding with the Excessive Deficit Procedure regarding Germany and France, many observers concluded that the Pact was dead or at least "suspended". No doubt the decision violated the spirit of the SGP. Yet, it was nothing else but the application of the rules: contrary to the original idea of automaticity of sanctions proposed by the German finance minister Theo Waigel in 1995, the Pact stipulated the need for a vote by the Council and therefore implied the possibility that the Commission might be overruled. The Commission requested Germany to reduce its structural deficit by $0.8 \%$ of the GDP, and France by $0.4 \%$. This recommendation was blocked and thereby also the consequence of imposing sanctions if these countries would not comply. What appeared so shocking about the events in 2003 was the fact that the decision to not follow the Excessive Deficit Procedure was taken so early in the Pact's life and as a consequence of bullying by the two largest member states and without genuine economic reasons. In other words, the procedures of the Pact have never been fully applied. Together with the serious policy divergences over the Iraq war and the failure of agreeing a European constitution, the SGP is the third major issue in less than one year that undermines the political credibility of European integration. I believe that this fact is not just to be blamed on incompetent or unwilling politicians; rather it is intrinsic to the issue of fiscal policy coordination in an incomplete federation. It is a constitutional issue.

\section{The economic issue}

The SGP has been as widely criticized, as it has been acclaimed. Commission President Romano Prodi has called it "stupid, because rigid", while Artis

\footnotetext{
${ }^{1}$ Professor at the London School of Economics (www.stefancollignon.de).
} 
(2002) hailed it as "one of the most remarkable pieces of policy coordination in world history". Most probably, truth lies somewhere in between and it is useful to recall the logic behind the Pact.

The SGP tried to respond simultaneously to two major policy requirements: (1) protecting euro-stabilization policies by defining the aggregate fiscal policy stance necessary as a complement to the monetary policies of the European Central Bank and (2) an instrument to sanction free-riders who might destabilized the macro economy or the financial system by deviating policies in pursuit of narrow national interests. The two motives are partially interdependent. What has been the experience with the SGP?

First, as is well known, unconstrained fiscal policy can destabilize monetary policy and cause inflation. One needed therefore a safety mechanism to protect the ECB's autonomy and independence in pursuing price stability. The SGP achieved this objective by stipulating that each member state had to balance its structural deficit (or, to quote the official text, to aim for "medium-term objectives of budgetary positions close to balance or in surplus"). For if each country kept its budget in equilibrium, the aggregate budget position of the Union (more specifically Euroland) would also be balanced. Automatic stabilizers could contribute to the smoothing of the business cycle and the ECB had sufficient margins for the fine-tuning of monetary policy. Calculations by the European Commission have shown that under normal conditions the 3 percent margin of avoiding excessive deficits were sufficient to ensure the unconstrained functioning of automatic stabilizers, provided the structural budget objective was adhered to. But in reality, Euroland's structural budget has never been in balance. With the exception of 1999 and 2000 (when it was lower), it has remained at a stable deficit around $2.3 \%$.

The official interpretation of the Pact has come under criticism from two sides. First, countries like Germany and France argued that the deterioration in the business climate after 2001 prevented them from fully implementing the consolidation of their budget positions and therefore the swings of automatic stabilizers should have allowed them to go above the required $3 \%$ limit. As a consequence, the aggregate fiscal stance should also adjust more flexibly to the business climate. This is a request for vertical budget flexibility. However, the argument is confused. The business cycle should only affect the cyclical component of deficits, not their structural part. Theoretically, it would be possible to reduce structural deficits and at the same time increase cyclical deficits if demand is insufficient. However, in reality, both Germany and France implemented tax reforms, which increased the structural deficits. Germany's structural deficit was below 1.9\% of GDP between 1998 and 2000 , but stayed above $3.2 \%$ in every year since 2001. In France it rose from below $2.3 \%$ to more than $3.6 \%$. In Germany that reflected a desperate attempt to redistribute the burden of transfers (still!) related to German unification. In France, it was a direct consequence of the policy shift after the 2002 elections. Either way, the problem was less the business climate after a series of exogenous shocks (end of the Clinton-boom, 9/11, Iraq war), but the management of domestic policy objectives. The two recommendations by the Commission seem to be rather modest in this context. In other words, the economic issue was exactly what the Pact was intended to deal with; the difficulty of implementation was political. 
On the other hand, it has been argued that even if an overall balanced budget position for Euroland might be desirable, "one rule fits all" was too restrictive. Horizontal flexibility is required. Why should some countries not be allowed to spread public investment over a period of several years? Especially if a country's debt/GDP ratio is low, higher deficits could be affordable. Yet, in the context of a balanced or at least stable budget for the aggregate fiscal stance this argument implies that some countries should be saving for others to be able to borrow. Otherwise the deficits by one country would increase interests rates for all. This idea of horizontal flexibility may be economically reasonable, but it crudely lacks political legitimacy. Who should decide who saves how much and who is allowed to borrow?

Second, how serious has the free-rider problem been? It has been argued that given the "no bail-out clause" in the Maastricht Treaty, excessive government debt would increase the default risk and could destabilize the banking system and weaken the euro. This has not been the case. Except for the countries which have broken the excessive deficit rule, i.e. Portugal, Germany and France, the debt/GDP ratio has fallen or remained stable in all member states since 1999. The highest increase has been Portugal (from 54.3 to $59.5 \%$ ) and France (from 58.5 to $62.3 \%$ ). In Germany, the debt/GDP ratio fell from $61.2 \%$ in 1999 to 59.5 in 2001 and then increased again to $62.7 \%$. On the other side, it has fallen in Italy from $115 \%$ to $106 \%$ in 2003 . These developments have had little effect on financial markets. The default risk premium for government debt remains negligible in all countries. And the Euro exchange rate seems to evolve in total independence of fiscal policy: if the euro ever weakened due to fiscal policy, it was in 1999 after the Commission reprimanded Ireland for its economic policy choices under the Broad Economic Policy Guidelines, but not under the SGP. Moreover, since Germany and France first broke the 3\% limit, the euro has strengthened by more than $30 \%$. Hence, so far it does not seem that the occurrence of "excessive deficits" has had the negative consequences that many economists anticipated. Euroland's financial system remains stable.

Does this mean the Stability and Growth Pact is superfluous? Hardly. There is definitely a need to coordinate fiscal policy in a monetary union and to have mechanisms to sanction deviating behaviour. But the argument is more about stabilization policies and the optimal mix between fiscal and monetary strategies, than about financial stability. The logic of collective action is such, that a group of 13 or more member states will not be able to provide the optimal fiscal policy stance by voluntary coordination of their fiscal budget policies.

In recent years the intricacies of defining and implementing a coherent fiscal policy for Euroland has become a gold mine for economists and (usually self-appointed) policy advisors. It seems to me, maybe due to my limited imagination, that nearly any possible reform of the SGP has been proposed and discussed: expenditure or debt targets instead of deficits, golden rules, tighter or laxer rules, pro- or anti-cyclical policies, market mechanisms instead of government involvement, expert committees rather than politicians to decide budget limits, tradable deficit permits and using the discountability of public debt with the ECB as a sanctioning instrument and all kinds of different combinations between them. I easily could produce some further reform proposals. However, I believe all these technocratic 
"solutions" will lead to nowhere unless the fundamental issue is tackled: the democratic deficit.

\section{The political issue}

In fact, fiscal policy is at the heart of the political decision making process. The "power to tax" carries normative implications, which in a modern market economy require that individual citizens (largely concordant with tax payers) are the ultimate sovereign of budget decisions. By retaining fiscal policy at the national level, the Maastricht Treaty has established a splintered polity for European fiscal policy. The theory of fiscal federalism has established the "principle of fiscal equivalence" (Olson 1969), which requires that the incidence of benefits derived from collective goods should coincide with the jurisdiction of governments. Yet, this is not how fiscal policy functions in Euroland. Given the same currency, all fiscal policy decisions have potentially effects on prices, interest and exchange rates, i.e. on public goods that concern all citizens in the monetary area. However, the ability of citizens to control these effects are only indirect through national governments. National jurisdictions are by definition only small parts of the monetary union. Quite naturally governments optimize policies in order to get re-elected in their national constituency, while the definition of a European fiscal stance requires optimising policies over the whole constituency of Euroland. That would require a centralized fiscal function, a European government. This is in accordance with the theory of fiscal federalism that has established a long time ago that the strongest case for fiscal centralization is with respect to stabilization policies. The argument does not necessarily preclude the allocation function from remaining under national government authority, but it shows the need for a strong binding coordination mechanism.

As the events of November 2003 show, intergovernmental policy coordination fails to produce such binding solutions. Governments arrive in Brussels with predetermined preferences and settle on bargains that may minimize losses with respect to specific government objective functions, but they are not necessarily optimal for the whole area. Furthermore the perception of the bargain is nearly always negative. For ordinary citizens a loss is perceived as a loss, minimized or not. The reason is that citizens see their government as defending "their" interests, rather than the collective European interest for which no constituency exist. This fact systematically undermines the legitimacy of all European decisions, which are likely to constrain national policies. Some have argued that this is the price that must be paid for a common currency. But the issue is not whether countries (whatever that may be) have been prepared to relinquish some national sovereignty in exchange for the benefits of monetary stability. The problem is the democratic legitimacy of European policy making. The European Commission is charged to uphold "the general European interest". But how is that defined? Democratic theory would suggest that it is derived from European citizens' preferences and deliberations. But this implies a democratic process (and a European constituency) through which the general interest is formed and expressed, so that the Commission could then represent it. But this is not how things work in Europe. Given that fiscal 
policy is under the exclusive domain of governments, there are only "particular interests in Europe" that can claim democratic legitimacy. The commission appears as a burocratic clearing-house at best. No European Pact, however economically sound or desirable, will ever have the legitimacy of nationally elected governments when prescribing policies of taxation and spending. Can any democrat seriously think that a government that promises to cut taxes and increase deficits, and gets elected, like in France in 2002, could turn around and say to its voters: "Sorry, you wanted us to implement our policies, but the Commission and other member states or even the European Court of Justice do not allow us to do so"?

The SGP had to collapse because it is normatively incoherent with democracy. In the medium term, the answer should be to delegate the definition of the desirable collective fiscal policy stance to a European Government. This government must be accountable to all European citizens as its proper constituency. The allocational functions of public finance could still be exerted by national governments, that is to say, the EU-budget will not have to take over national governments. Yet, this EU-government, presumably grown out of the European Commission, must have the legitimacy to constrain national governments because it reflects the authority of European citizens. It therefore could tackle both dimensions of fiscal policy in Europe: the stabilization and the sanctioning function. The popular acceptance of the resultant policy decision would be improved, because they would reflect the collective deliberation of what is best (or least bad) from the point of view of Europe's collective interest.

Of course, this idea is provocative. Maybe it is utopian. But it is derived from the norms, rules and conventions, on which European public life is built. The creation of European monetary union has created a large new class of collective goods, which affect all European citizens. They have a right to be involved in their management. In my recent book, I have called this the European Republic (Collignon, 2003). Thus, the real issue behind the "suspension" of the Stabilization and Growth Pact is constitutional. Will the European Union find the will to jump to a political union, or will Europe return to its historic pattern of warring states?

\section{References}

Artis MJ (2002) The Stability and Growth Pact: Fiscal Policy in EMU. In: Breuss F, Fink G, Griller S (eds) Institutional, Legal and Economic Aspects of the EMU. Springer, Wien, New York

Collignon S (2003) The European Republic. Reflections on the Political Economy of a Future Constitution. The Federal Trust/Kogan Press, London

Olson M (1969) The Principle of 'Fiscal Equivalence': The Division of Responsibilities among Different levels of Government. In: American Economic Review, Papers and Proceedings 59: 479-487 